\title{
Development and implementation of a miniature RFID system in a shopping mall environment
}

\author{
Ademola Abdulkareem, Awosope C.O.A, Tope-Ojo A. E \\ Department of Electrical and Information Engineering, Covenant University, Ota, Nigeria
}

\begin{tabular}{l}
\hline \hline Article Info \\
\hline Article history: \\
Received Dec 28, 2017 \\
Revised Jun 28, 2018 \\
Accepted Oct 17, 2018 \\
\hline Keywords: \\
C\# programming language \\
Desktop \\
Miniature RFID \\
MySQL database \\
Shopping mall
\end{tabular}

\begin{abstract}
The advancement of technology has brought about the need for industrial innovation. One area where innovation is required in a developing country is in the retail industry (this is the focus point of this project) where the present system that is the barcode technology is old and archaic. This project is based on the use of Radio Frequency Identification (RFID) technology to create a faster, easier and more secured checkout system. This paper showcases the development of a miniature RFID desktop application that can be used for registering items coming into a shopping mall, checking out of goods bought from the shopping mall and the detection of an attempt to steal goods from the shopping mall, using both C\# programming language and MySQL for the database management.
\end{abstract}

Copyright $\odot 2019$ Institute of Advanced Engineering and Science. All rights reserved.

\section{Corresponding Author:}

Ademola Abdulkareem,

Department of Electrical and Information Engineering,

Covenant University,

KM 10, Idiroko Road, P.M.B. 1023, Ota, Ogun State, Nigeria.

Email: ademola.abdulkareem@covenantuniversity.edu.ng

\section{INTRODUCTION}

The process of identifying physical objects is a fundamental part of our experience that we seldom think about how we do it [1]. We pick up an object, look at it, smell and probably (when possible) taste the object, until we develop a reference particular to that specific object or we can say that we give it a label, unique to the characteristics that was picked up by our senses regarding the object. Just as we can recognize things using the information which our senses send to us, so can computers. Computers can identify or recognize physical entities only by the one sense system they have, and these are called sensors. Radio Frequency Identification (RFID) is one of the best digital identification technologies amongst other digital identification technologies including Barcode Systems, Optical Character Recognition, Biometric procedures including voice identification, fingerprinting procedures. In a retail environment, that involves the selling of goods directly to customers, identification of the goods sold is a crucial concern. And going from mall to mall, it was increasingly observed that the method of using barcodes to identify goods to be bought by customers is not only painstaking; because of the long waiting time before the customer is attended to, it is also time consuming, hence, the RFID can be considered as the successor of the Barcodes.

RFID is an automatic identification system that stores data and information on devices like RFID tags and RFID readers using electromagnetic coupling in the radio frequency portion of the electromagnetic spectrum [2]. RFID contains the promise of real-time identifying, locating, tracking (attendance and vehicle tracking), and monitoring physical objects, and can be used for a wide range of antennas to fit an equally wide range of tags, readers, and systems [3]. The RFID technology has been in existence for a while now, with most of the valuable research is being done in the U.S.A, India, and other developed countries. For instance, Arun [4] carried out various reveiews of RFID applications; Deng [5] worked on a new approach of tracking vehicle based on RFID; Yonghai, et al. [6] proposed RFID application of spatio-temporal data 
management; Li [7] worked on ID-based strong designated verifier signature scheme with message recovery which was provably secure and efficient; The current study of Cakir, et. al. [8], aimed to reveal RFID personnel control by the employer that can be managed via 4.5 G. In India, major current applications of RFID research being undertaken are on the antenna for RFID applications [9]-[12] and that has led to technological advancements. Moreover, various retail outlets in developed countries are making use of this tremendous technology to increase sales, improve customer satisfaction level, and increase their stockstaking efficiency amongst many other benefits that will be provided to the retail outlet because of the use of the RFID technology.

Coming home to Nigeria, the application of this technology is at its barest minimum, shopping malls and even large retail outlets still make use of the manual method of taking inventory of goods, manual method of checking around the mall to determine if a particular item has been sold out, archaic barcode reading method used at the point-of-sale terminal, manual checking of all items which a customer has bought; verifying if the items with the customer tallies with the list of items on the receipt. This research work, though focused at creating a mini version of a real retail implementation of the RFID technology, is aimed at showcasing different basic features that can be utilized by a small modelled retail outlet.

\section{RESEARCH METHOD}

This desktop retail application is developed using the C\# programming language with the aid of the Visual Studio 2013 IDE (Integrated Development Environment) and for the database management, MySQL database language was utilized. For the hardware portion of the work, the RFID reader module used was ID20LA RFID Module (Reader) which is a small device that can read RFID tags of the low frequency range $125 \mathrm{KHz}$. To connect the RFID module to the computer, a RFID USB Reader was used, which is a small PCB board with onboard female pins for the male pins of the RFID module to comfortably sit-in and thus connect the module to the computer through a serial connection. And lastly, different $125 \mathrm{KHz}$ RFID tags making use of the EM4001 ISO-based RFID IC was used to represent items that can be purchased by a potential buyer. The core features developed in the application include: Registration Point, Counter Checkout Point and Anti-Theft Point.

\subsection{Registration phase}

This phase of the system is the entry point of items into the system's database. At this phase, new items are registered into the database. Figure 1 shows the flowchart diagram for the registration phase. Scenarios to be tested in this phase include the following: Registering a new item into database and attempting to register a registered item.

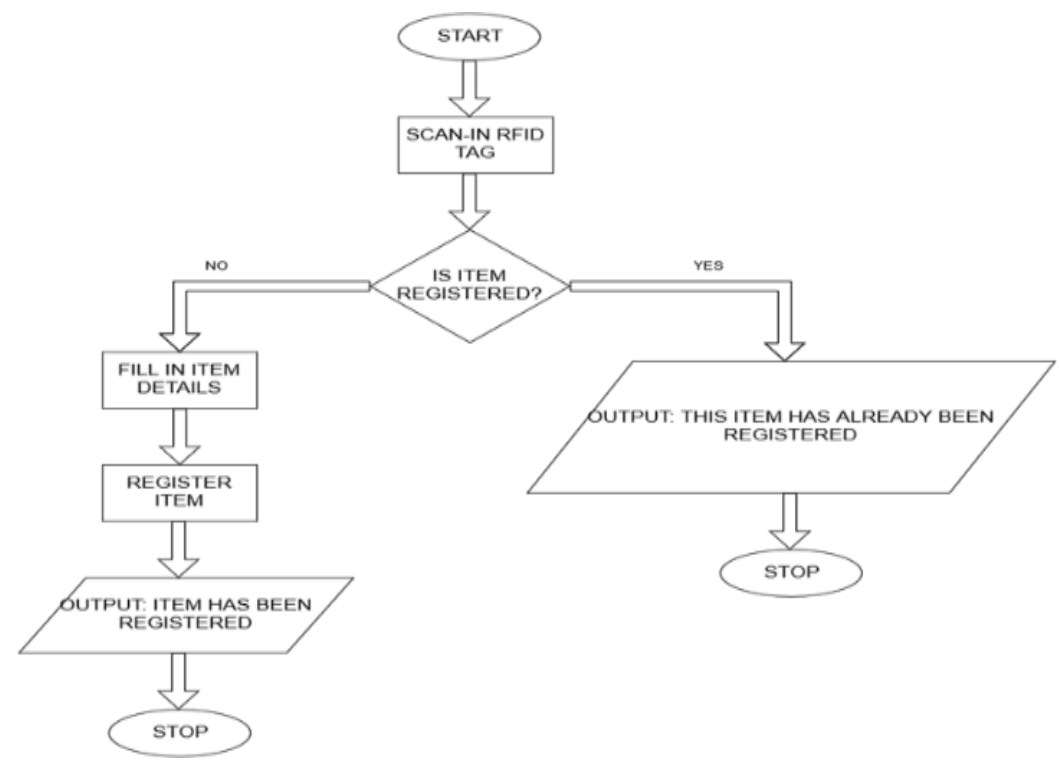

Figure 1. Flowchart diagram for registration phase 


\subsection{Counter checkout phase}

This is the simulated shopping mall phase, where items (that have been duly registered into the database) that are to be bought by a customer are scanned and checked out accordingly. Figure 2 shows the flowchart diagram of this phase. Scenarios to be tested in this phase include the following: (i) A case where an item is not registered to the system's database when a customer brings it for checkout. (ii) Checking out a registered item.

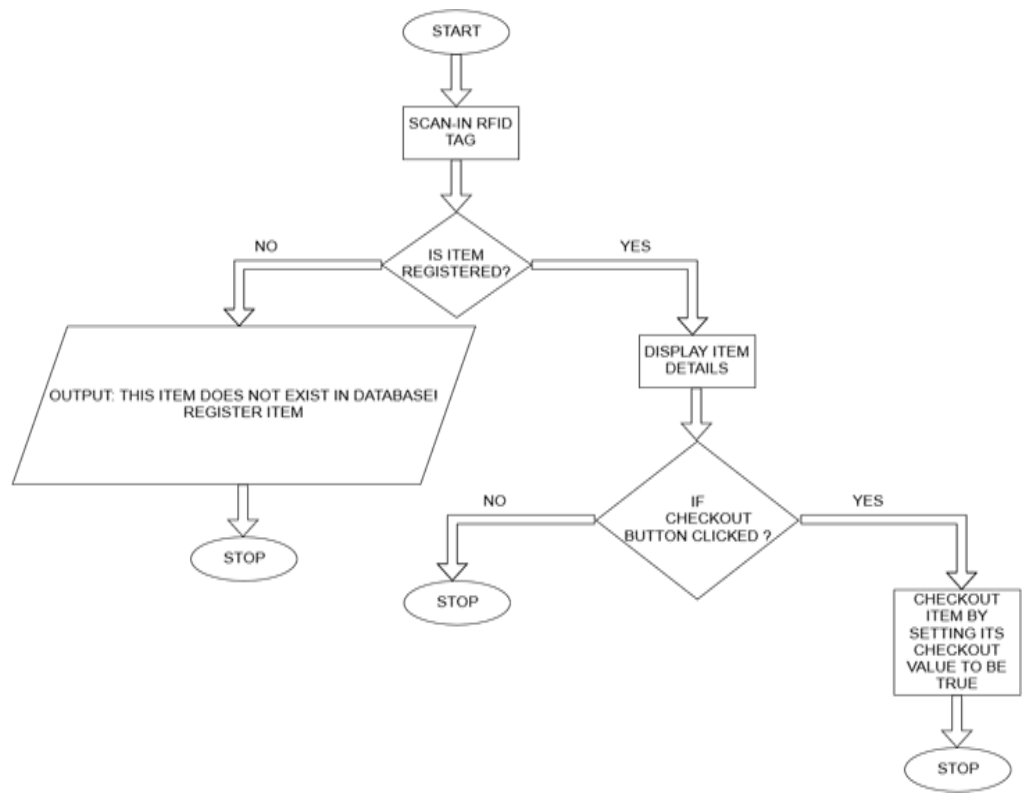

Figure 2. Flowchart diagram for counter checkout phase

\subsection{Anti-theft phase}

This phase of the system simulates the event whereby the RFID reader is mounted at the entrance of the shopping mall. It checks to know if any item of goods being taken out of the mall has been cleared and checked out. The flowchart diagram for this phase can be seen in Figure 3. The scenarios to be tested in this phase include the following: (i) checking when a cleared item is passed through the reader. (ii) Checking when a registered but un-cleared item is passed through the reader.

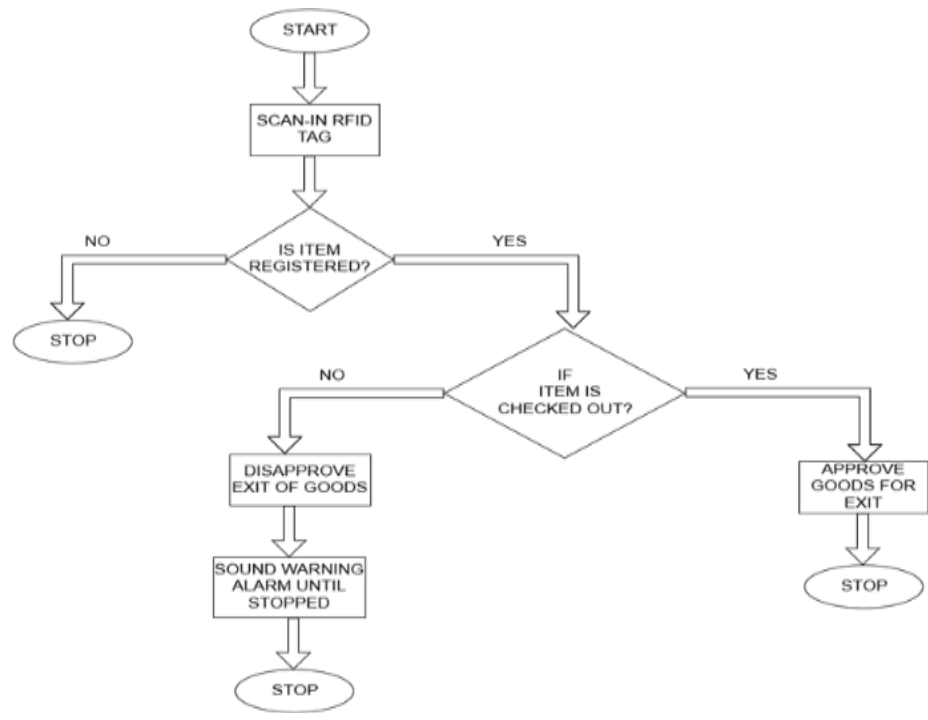

Figure 3. Flowchart diagram for anti-theft phase 


\section{RESULTS AND ANALYSIS}

This portion of the software implementation report shows the snapshots of the results of the scenarios tested on the developed desktop application according to the phases of the implementation. Figures 4 and 5 present the scenarios of Registration Phase at database for new item and registered item respectively. Figures 6 and 7 also present the scenarios of counter checkout Phase for un-registered item at the counter and the successful checkout of an item respectively. The Scenarios of Anti-Theft Phase of alarm alert for an attempted theft and a cleared item approved for exit are as shown in Figures 4 and 5 respectively

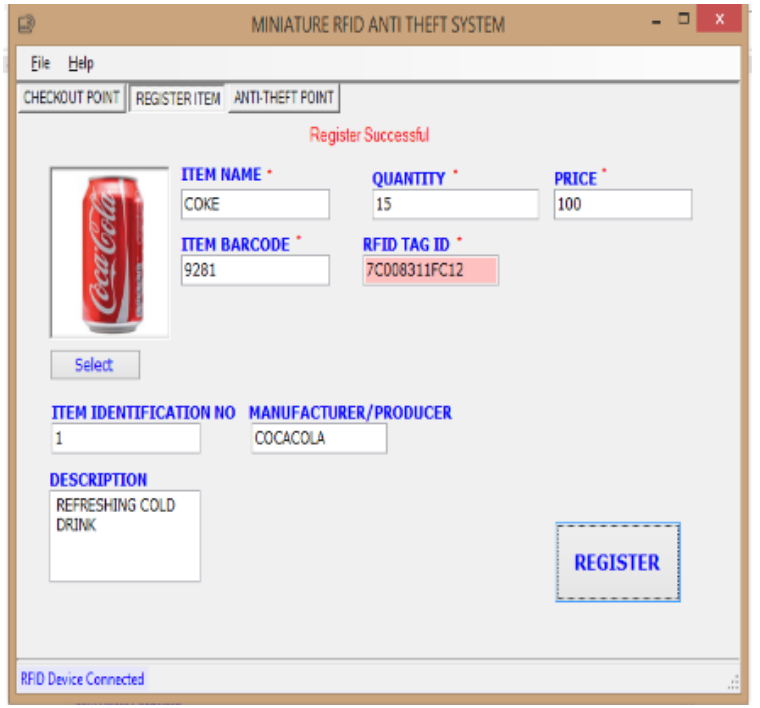

Figure 4. Registering a new item into database

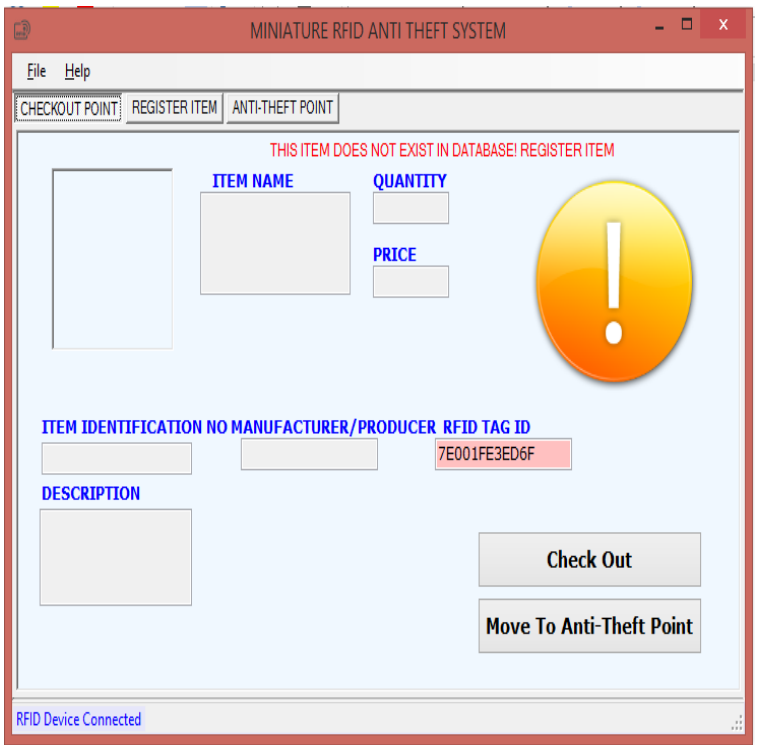

Figure 6. Scanning an un-registered item at the centre

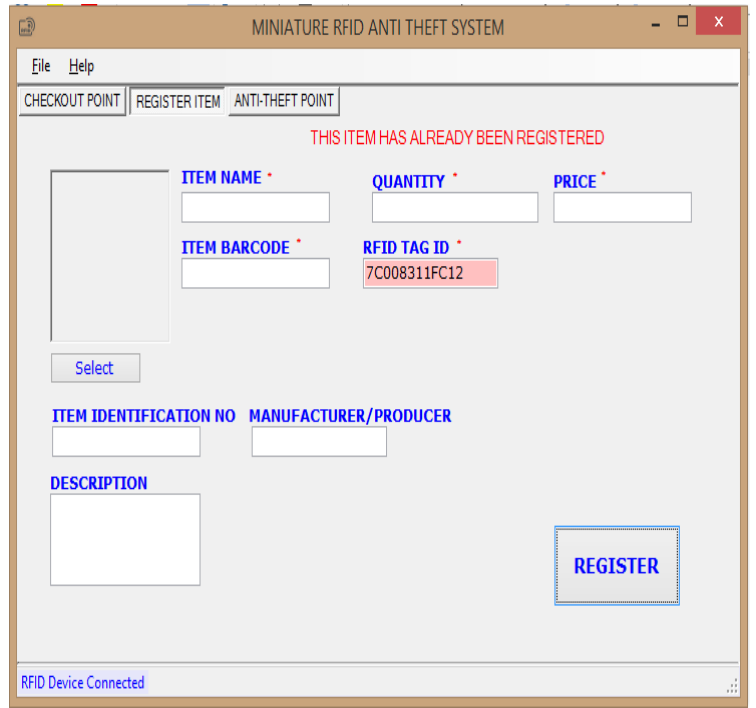

Figure 5. Attempting to register a registered item

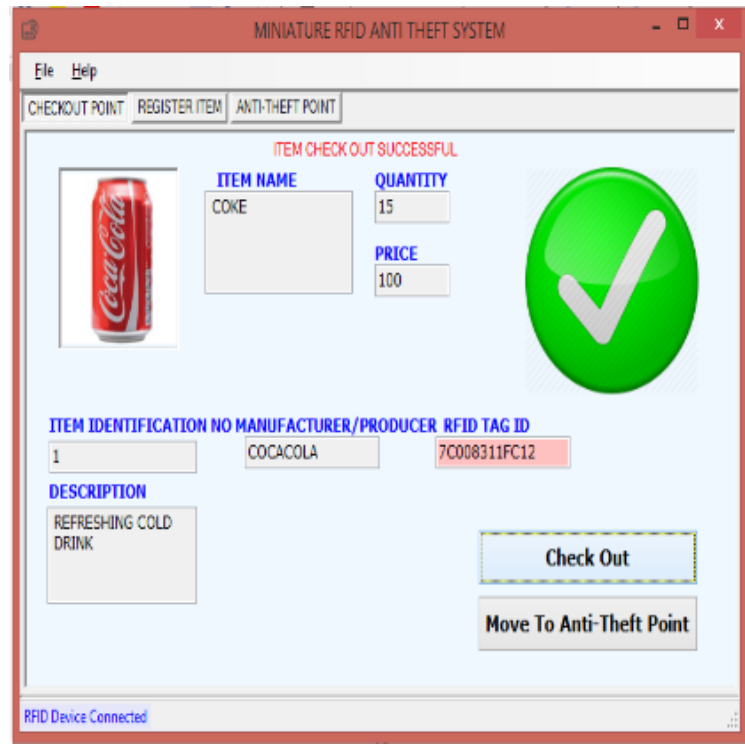

Figure 7. Successful checkout of an item 


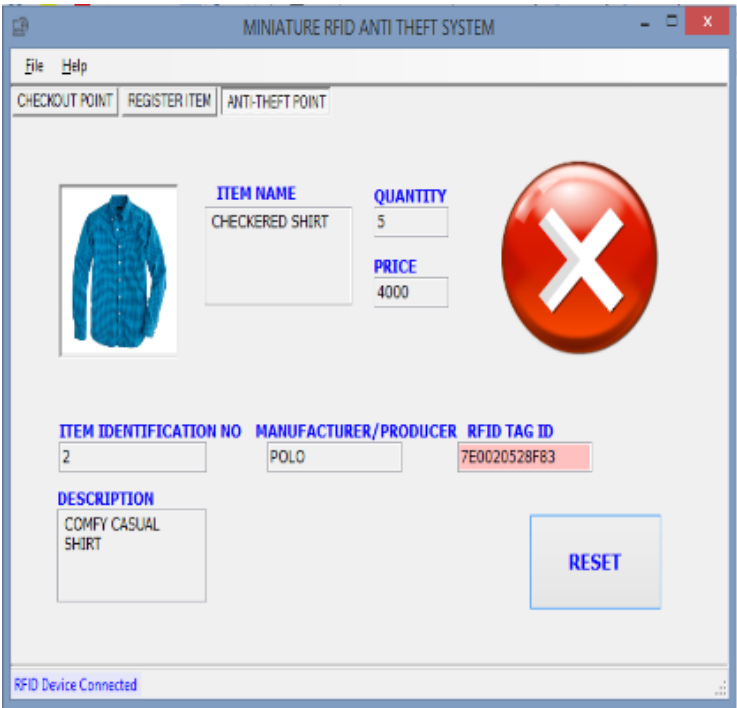

Figure 8. Alarm alert for an attempted theft

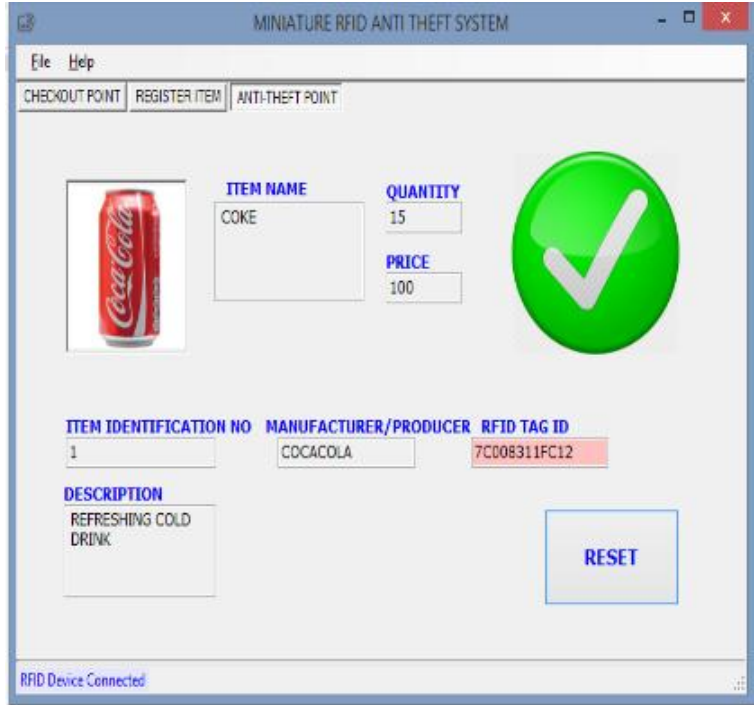

Figure 9. A Cleared item approved for exit

\section{CONCLUSION}

The RFID technology's potentials cannot be defined yet, because more research is being done in that field which reveals more areas of life that RFID can improve. This research work was focused on the application of the RFID technology in the retail environment, where a miniature anti-theft system was developed with item registration feature, counter checkout feature and an anti-theft feature. More features and even more sophisticated benefits of applying the RFID technology to the retail environment have been developed and more are still in research to improve the overall efficiency, accuracy and customer satisfaction

\section{ACKNOWLEDGEMENTS} this work.

The researchers are grateful to Covenant University, Ota, Ogun-State, Nigeria for sponsoring

\section{REFERENCES}

[1] Igoe., "Tim. Getting Started with RFID," O'Reilly Media, Inc., 2012.

[2] A. Abdulkareem, D. U. Ike, and F. Olowononi, "Development of a Radio Frequency Identification Based Attendance Management Application With A Pictorial Database Framework," International Journal of Research in Information Technology, vol. 2(4), pp. 621- 628, April 2014.

[3] C. M. Chen and L. S. Liu, "Applications of RFID Technology for Improving Production Efficiency in an Integrated-Circuit Packaging House," International Journal of Production Research, vol. 47(8), pp. 2203-2216, 2009.

[4] N. N.. Arun, "RFID Technology: A Review of its Applications," Proceedings of the World Congress on Engineering and Computer Science 2009 vol. 2, San Francisco, USA, 2009.

[5] J. Deng, "Achitecture Design of the Vehicle Tracking Sysem based on RFID," TELKOMNIKA Indonesian Journal of Electrical Engineering, vol. 11(6), pp. 2992-2997, 2014.

[6] W. Yonghai, X. Jingle and W. Shouijin, "RFID Spatio-Temporal Data Management," TELKOMNIKA Indonesian Journal of Electrical Engineering, vol. 11(3), pp. 1348-1354, 2013.

[7] M. Li, "Provably Secure and Efficient ID-Based Strong Designated Verifier Signature Scheme with Message Recovery," Indonesian Journal of Electrical Engineering, vol. 12(10), pp. 7343-7352, 2014.

[8] A. Cakir and H. Kaygisiz, "RFID Personnel Control System that can be Managed via 4.5 G," Indonesian Journal of Electrical Engineering and Computer Science (IJEECS), vol. 2(2), pp. 396-408, May 2016.

[9] Y. Gnih, et. al., "A Miniature RFID Antenna at UHF Band using Meander-Line Technique," International Journal of Electrical and Computer Engineering (IJECE), vol. 8(4), pp. 2280-2289, August 2018.

[10] M. Ihanji, et al., "Design of Compact Tri-Band Fractal Antenna for RFID Readers," International Journal of Electrical and Computer Engineering (IJECE), vol. 7(4) pp. 2036-2044, August 2017.

[11] A. El-Hamraoul, et. al., "A New Compact CPW-Fed Dual-Band Monopole Anttenna for RFID Applications," Indonesian Journal of Electrical Engineering and Computer Science (IJEECS), vol. 8(1), pp. 69-76, 2017.

[12] N. M. Sahar, et. al., "Development of Reconfigurable Atenna for Advanced Tracking Technology," Indonesian Journal of Electrical Engineering and Computer Science (IJEECS), vol. 10(2), pp. 672-679, 2018. 